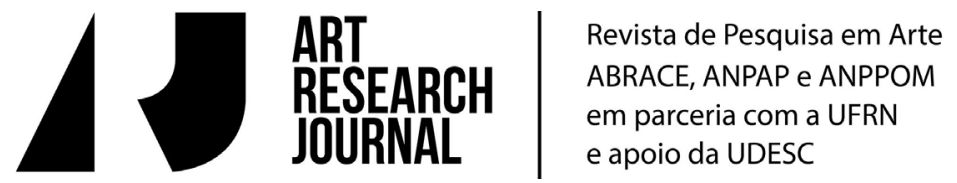

\section{A Cena Expandida: alguns pressupostos para o teatro do século XXI}

\author{
Gabriela Lírio Gurgel Monteiro \\ Universidade Federal do Rio de Janeiro, Brasil
}

O que é uma cena expandida? Como pensar a cena teatral hoje? Quais são seus limites, suas bordas, suas inscrições que denotam alguma especificidade? Por que já se falou de escultura expandida, filme expandido, literatura expandida e só recentemente pensamos a cena expandida, nesses termos? Vou tentar aqui chegar a algum tipo de delineamento para uma cena que tem como pressuposto o campo ampliado. Pretendo, como um desenho, delinear traços, rastros que a caracterize, com o objetivo de perseguir uma trajetória de análise, tomando o teatro como foco da proposição. Para situar a arte contemporânea, utilizo as terminologias expandida e ampliado, utilizadas pelo cinema, pela literatura, pelas artes visuais e, nesta análise, pelo teatro.

Rosalind Krauss em seu texto "A escultura no campo ampliado" (1979/2008) propunha um novo olhar sobre a escultura a fim de compreender e situar novas formas de produção da escultura nos anos 70/80. Krauss defendia que a escultura precisava ser revista e compreendia a ampliação do campo em duas vias - a primeira, em referência à prática artística, e à segunda, em referência ao meio de expressão, ambas a partir da ruptura com as condições do modernismo. Nesse sentido, diz Krauss, "muitos dos artistas em questão se viram ocupando, sucessivamente, diferentes lugares dentro do campo ampliado" (Krauss, 2008, p. 136), em uma trajetória desordenada e contínua para além da demanda de pureza modernista. A prática não pode mais, defendia Krauss, ser definida em relação ao meio de expressão, mas através de um "conjunto de termos culturais para o qual vários meios - fotografia, livros, linhas em parede, espelhos ou escultura propria- 
mente dita - possam ser usados" (Krauss, 2008, p. 137), o que fez com que muitos artistas ocupassem diferentes lugares dentro do campo ampliado da escultura. Assim, por exemplo, a obra de um artista como Joel Shapiro envolve a criação de imagens da arquitetura dentro de espaços extensos (paisagens). A contribuição da análise de Krauss deve-se à defesa da autora por uma crítica não reducionista que, ao contrário de diminuir os efeitos de um campo novo e de difícil assimilação, pela ausência de fronteiras e pela multiplicidade de combinações, redefine o campo da escultura como o das relações entre as artes. Campo ampliado é, portanto, uma rede de friç̧ão e de indefinição; sua riqueza reside exatamente no não-aprisionamento de formas artísticas. Por outro lado, nessa perspectiva, torna-se relevante compreender a lógica dos contextos históricos nos quais estamos inseridos, levando em consideração vetores de mobilidade e novos processos de subjetivação. A arte deveria se aproximar das coisas comuns, das experiências cotidianas. Do surgimento do texto de Krauss à arte do século XXI, surgem inúmeros contextos expressivos, nos quais a produção e a recepção artísticas denotam que a tecnologia, a ciência e a arte tornam-se cada vez mais interligadas. Princípios de interatividade e conectividade exigem novos paradigmas para a crítica da arte, tal como aponta Couchot quando discorre sobre o modo como as imagens digitais estabelecem novas formas de interação entre aqueles que as criam e as vêem. Segundo ele, há um processo de hibridização latente entre sujeito, objeto e imagem, o que leva a uma nova característica de subjetividade.

De acordo com Roy Ascott, por exemplo, a subjetividade não estará mais localizada num único ponto do espaço, mas distribuída por meio de redes; de acordo com Sigfried Zelinski, subjetividade é a possibilidade de ação na fronteira das redes; de acordo com Pierre Lévy, a subjetividade tornou-se fractal ... (Couchot, 2009, p. 399).

Na literatura, Florência Garramuño, em Frutos Estranhos: sobre a inespecificidade da estética contemporânea (2014), faz uma preciosa análise do momento atual, apontando não só para a inespecificidade das artes que constituem o campo expandido, mas para comunidades em expansão que marcam uma literatura fora de si. O estar fora de si da literatura advém de um sentido de não pertencimento e, ao mesmo tempo, de interdisciplinaridade, do entrecruzamento das artes. 0 não pertencimento é relativo à desconstrução de uma ideia de origem, do sentido de 
pertencer a apenas uma comunidade, do domínio técnico de uma arte específica. Garramuño aposta no inespecífico no interior de uma mesma linguagem, o que leva a uma radicalização extrema no fazer artístico literário.

Essa aposta no inespecífico seria um modo de elaborar uma linguagem do comum que propiciasse modos diversos do não pertencimento. Não pertencimento à especificidade de uma arte em particular, mas também, e sobretudo, não pertencimento a uma ideia de arte como específica. Seria precisamente porque a arte das últimas décadas teria abalado a ideia de uma especificidade, além da especificidade do meio, que cada vez há mais arte multimídia ou o que poderíamos chamar de "arte inespecífica" (Garramuño, 2014, p. 16).

Relacionar a arte inespecífica à arte multimídia, leva-nos a pensar a prática contemporânea artística como uma prática em trânsito ou como arte inespecífica, tal como Garramuño defende. O artista, deslocando-se entre disciplinas, inaugura - através das trocas estabelecidas entre os meios - novos modos de produção e, também, de recepção e circulação de sua criação. Não há como categorizar as obras, pelo menos não mais quanto a sua especificidade, a não ser analisando-as caso a caso. Na literatura, temos experiências relevantes com a incorporação de inúmeras linguagens e suportes (e-mail's, blogs, fotologs, fotografias, imagens, etc.), o que leva à multiplicação de formas discursivas. O que temos tanto na literatura, como nas artes visuais contemporâneas, é a heterogeneidade de produções artísticas.

No cinema contemporâneo, é interessante a problematização dos dispositivos, pensados sob diversos aspectos - aparelho ou máquina; construção epistemológica, disciplinar ou de sexualidade. Interessa refletir sobre o dispositivo como agenciamento, inaugurando novos regimes de visibilidade e de produção do imaginário. Voltemos à ideia de comunidades ou redes; assim os agenciamentos devem ser percebidos, de um lado autonomamente, de outro, interligados a outras experiências e perspectivas. A ideia de um cinema expandido, fora do padrão do cinema clássiconarrativo (exibido em uma sala escura para espectadores); um cinema que rompe com a estrutura espacial e põe à prova não só o espaço, como também a forma de produção e recepção, criando "novos equipamentos coletivos de subjetivação" (Parente, 2009, p. 34) trouxe grande contribuição à arte contemporânea. O cinema expandido, segundo Parente, se caracteriza por duas vias: a reinvenção da sala de cinema em novos espaços (quando, por exemplo, o cinema invade o museu) e as instalações que "radicalizam processos de hibridização entre diferentes mídias" ( $p$. 
41): instalações imersivas, ambientes virtuais panorâmicos, criando o que Dubois chama de "efeito-cinema". Um efeito que não é novo, remonta aos anos 90, e que relativiza a própria ideia de cinema e de arte. "Um efeito cinema", de todo modo, extremamente diversificado e multiforme. E que opera em todos os níveis: nos planos institucional, artístico e teórico (ou crítico)" (Dubois, 2009, p. 181).

À primeira vista, opero aqui uma breve contextualização histórica na qual surge o campo expandido da arte, levando em consideração subáreas específicas, como a literatura, o cinema e as artes visuais. Pode parecer contraditório esta divisão primeira, mas parto da hipótese de que o debate sobre a cena expandida não se constrói através de uma divisão entre saberes, mas historicamente promove interrelações e novos agenciamentos a partir das articulações estabelecidas entre as artes, o que traduz a inespecificidade dos campos artísticos contemporâneos. Ainda que tenhamos debates em momentos históricos e abordagens diversas na literatura, nas artes visuais, no cinema, no teatro e nas demais artes; é fato que estamos diante de uma zona de contaminação que transforma suas fronteiras em zonas de indefinição, levando a formas híbridas de criação. As artes cênicas que sempre estiveram associadas às demais artes (como a música, as artes visuais e, evidentemente, a literatura), a partir do surgimento do cinema, apropriam-se de técnicas as quais, com o advento do digital, nos anos 90, ampliam um vasto campo de experimentações.

\section{Encenações híbridas: artes intermediais}

No teatro, chamo de cena expandida aquela que não se circunscreve apenas ao fazer teatral, como àquele associado aos modos de produção e recepção teatrais convencionais, mas também se articula diretamente a áreas artísticas distintas, em uma espécie de convergência que tangencia conhecimentos oriundos das artes cênicas, visuais, das mídias audiovisuais, da performance, da dança, da literatura, da fotografia.

Segundo Patrice Pavis, o termo cena "conhece, ao longo da história, uma constante expansão de sentidos: cenário, depois área de atuação, depois o local da ação, o segmento temporal no ato e, finalmente, o sentido metafísico de acontecimento brutal e espetacular" (Pavis, 1999, p. 42). É evidente que o uso de tecnologias 
digitais, somado ao hibridismo de linguagens na cena, modificou a percepção do acontecimento teatral e seu sentido metafísico, como atribuído por Pavis. A cena teatral contemporânea apresenta um esvanecimento das fronteiras entre as artes e, junto com isso, a dificuldade de delimitação da produção artística que não mais aparece de forma definida. Obras de artistas e grupos como Phila 7, Felipe Ribeiro, Christiane Jatahy, Enrique Diaz, Robert Lepage, Bob Wilson, Mariane Weems, Wooster Group, Rimini Protokoll, Laurie Anderson, entre muitos outros, traduzem a pluralidade de pesquisas ligadas ao teatro, à performance, ao cinema/audiovisual, à poesia, à instalação, à dança, à ópera.

"O que caracteriza a cena teatral contemporânea?" é questão relevante para autores como Hans-Thies Lehmann, Josette Féral, Béatrice Picon-Vallin, Izabella Pluta, entre outros. A ideia de cena é transformada ininterruptamente pela estimulação e experienciação de novos modos de utilização dos dispositivos e dos recursos tecnológicos. Silvia Fernandes, em referência ao conceito de teatro pós-dramático desenvolvido por Lehmann, analisa a pluralidade fragmentária da cena contemporânea na tentativa de traduzir a exaustiva cartografia realizada pelo autor:

... o conceito de pós-dramático vem juntar-se a uma série de nomeações que, há pelo menos três décadas, tenta dar conta da pluralidade fragmentária da cena contemporânea, especialmente dessas espécies estranhadas de teatro total que, ao contrário da gesamtkustwerk [sic] wagneriana, rejeitam a totalização, e cujo traço mais evidente talvez seja a frequência com que se situam em territórios bastardos, miscigenados de artes plásticas, música, dança, cinema, vídeo, performance e novas mídias, além da opção por processos criativos descentrados, avessos à ascendência do drama para a constituição de sua teatralidade e seu sentido. (Fernandes, 2010, p. 43).

Apesar das dificuldades encontradas no percurso teórico do autor que, na tentativa de caracterizar o teatro pós-dramático, não aprofunda diferentes modos de criação estética, analisando um panorama bastante heterogêneo, ao longo de sessenta anos, cujo traço comum seria "o fato de se distanciar da órbita do dramático" (Fernandes, 2010, p. 50), o que torna, em alguns momentos, a análise pouco elucidativa, há de se notar o esforço do levantamento feito e a multiplicidade de processos de criação analisados.

Para Josette Féral, a investigação sobre a teatralidade e a performatividade engendra uma outra concepção da cena teatral. O teatro performativo, ao romper com a 
primazia do texto, modifica o sentido da cena ao trazer a questão do real, abalando as estruturas cênicas tradicionais - "um real fundamental, por vezes violento, que surge no cerne da representação e que interpela brutalmente o espectador" (Féral, 2011 , p. 10). Novas estratégias de recepção da obra teatral são, consequentemente, adotadas à medida que as fronteiras e os limites da cena são postos em xeque. Féral faz distinção do uso do real, desde os anos 60, pela performance (e a sensação de violência através da presença do corpo atuante do performer) e por demais cenas, como por exemplo no filme "A batalha do Chile", no qual o cinegrafista filma ao vivo a própria morte. O choque do real advém também da mobilidade do espectador que se vê diante de suportes vários, tentando traduzir a violência das imagens, da palavra, do corpo e, sobretudo, da interação entre linguagens distintas às quais se vê submerso e impelido a produzir sentidos que vão além dos limites da própria cena.

Nesse sentido, considero que a cena expandida modifica a recepção da obra artística, propiciando novos modos de percepção, levando o espectador ao lugar de agenciador da obra. Interagir com possibilidades múltiplas que vão desde o uso de dispositivos audiovisuais, passando por suportes distintos ao contato sensorial com materiais e espaços não convencionais, leva o espectador a experimentar um tipo de recepção em que se vê convidado a transitar entre tempos e espaços variados. É na articulação, no encontro, na intersecção entre tempos, espaços e no hibridismo da confluência entre as artes que situo a cena contemporânea.

Torna-se relevante, por outro lado, compreender que o advento da tecnologia digital, sobretudo dos anos 1990 em diante, provocou uma reconfiguração da imagem que ganha outro estatuto ao ser criada in loco, ao ser multiplicada na cena, seja uma cena circunscrita a um palco italiano, uma cena no "Parque Lage"1 com uso de projeções em árvores, uma instalação que se modifica ao som da coreografia de um bailarino.

Com o objetivo de compreender a complexidade e o hibridismo das formas artísticas contemporâneas, Pluta analisa alguns aspectos relevantes que compõem um novo modelo de recepção das obras. Entre eles, destacam-se o uso cada vez mais

\footnotetext{
1 Parque Lage é um parque público, tombado pelo IPhan, considerado patrimônio histórico e cultural da cidade do Rio de Janeiro. O parque recebe anualmente inúmeros eventos artísticos, além de sediar a Escola de Artes Visuais, que formou importantes artistas brasileiros e que atende a mais de 2000 alunos.
} 
intenso da Internet e de sistemas cibernéticos; novos modos de percepção que possibilitam diversas "sensorialidades" em face das tecnologias digitais; novas visões do corpo através das "transformações de identidade influenciadas pela virtualidade" (Pluta, 2011, p. 43). Há, ainda, segundo a autora, um hibridismo constante entre obras artísticas e o espaço cotidiano, o que aponta para um processo mais amplo no qual estamos inseridos e do qual muitas vezes não percebemos, vivenciado, de forma veloz, por novos modelos perceptivos de apreensão da realidade.

[...] o espetáculo tecnológico coloca em jogo as transformações perceptivas que compõem a cibercultura [...] as projeções integradas nesse tipo de espetáculo multiplicam o ponto de vista do espectador que se situa diante de uma multivisão. Representa uma importante consequência também para o ator que pode interagir diretamente com a câmera, assim como uma máquina de visão (Pluta, 2011, p. 48).

Paul Virilio defende um novo modo de percepção que se configura através da ausência da percepção imediata da realidade concreta, ou seja, estamos diante de videoperformativos (Virilio, 2014, p. 26) ou da videoperformance da transmissão das imagens (p. 27), em que a instantaneidade do momento atravessa distâncias antes impensáveis; o infinitamente pequeno transforma-se em infinitamente grande modificando a concepção científica de apreensão dos objetos. As profundidades de campo e de espaço são substituídas pela profundidade de tempo de exposição das imagens. A estética do desaparecimento proposta por Virilio vai de encontro à estética da aparição de uma imagem estável (analógica) presente em suportes físicos, como papel, tela, madeira, etc, dando conta de uma imagem instável (digital) que, em muitos casos, escapa à consciência de sua apreensão, tamanha a velocidade.

\section{Novas pedagogias - o ensino (trans)midiático nas artes da cena}

De que forma ver/ser através das imagens torna-se uma questão fundamental quando se trata da cena expandida, na qual temos a sensação de um tempo intensificado e acelerado, que não conseguimos nunca apreender e, por outro lado, a percepção de um espaço dilatado que se desdobra e se prolifera em muitos outros, igualmente inapreensível. Este novo olhar na/da cena inaugura-se com certa perplexidade e angústia. Para alguns estudiosos, como é possível situar um 
campo de pesquisa em território tão pouco tangível? Parece estar-se diante de um lugar frágil, de possibilidades tão infindáveis que não configuram um campo de articulação teórica sustentável. Há, ainda, uma falsa ideia de que, ao se criar uma cena expandida, se perde a capacidade de utilizar técnicas e procedimentos metodológicos baseados em estudos aprofundados da cena teatral. Como se não houvesse alicerces possíveis diante da profusão de conexões novas que se formam com os avanços tecnológicos e os cruzamentos entre as experiências criativas que surgem. Assim, para alguns, torna-se difícil compreender que uma cena intermedial pode ser consequência de um trabalho a partir do método das ações físicas, de Stanislavski, ou a partir das investigações do espaço vazio brookiano ou, ainda, da interrelação entre estudos da performance e a fotografia, para citar alguns exemplos possíveis. Como, afinal, questiona Rancière:

\begin{abstract}
Essas histórias de fronteiras por transpor e da distribuição de papéis por subverter confluem para a atualidade da arte contemporânea, na qual todas as competências artísticas específicas tendem a sair de seu domínio próprio e a trocar seus lugares e poderes. Hoje temos teatro mudo e dança falada; instalações e performances à guisa de obras plásticas; projeções de vídeo transformadas em ciclo de afrescos; fotografias tratadas como quadros vivos ou cenas históricas pintadas; escultura metamorfoseada em show multimídia, além de outras combinações (Rancière, 2012, p. 24).
\end{abstract}

Situar tais territórios miscigenados é um desafio, diferente da concepção heterogênea da gesamtkunstwerk wagneriana. Para Wagner, a obra ideal do teatro aproximava as artes, mantendo suas especificidades estéticas e suas expressividades individuais. Na contemporaneidade, não está mais em questão definir especificidades ou sublinhar individualidades. Parece-me que ignorar tais práticas artísticas ou seus efeitos nos processos de recepção da cena é se alijar de grande parte da produção cultural existente. Interessa, sobretudo, investigar as produções contemporâneas tomando a cena expandida como um meio de expressão artística que nasce da relação intrínseca entre o homem e a tecnologia, constituindo um diálogo profícuo exatamente por promover uma cena desierarquizada, na qual espectadores e atores trocam sistematicamente de lugar, expondo aquilo que não se sabe, que não se pode definir a priori, o que Rancière define como sendo "um idioma novo que traduz uma nova aventura intelectual" (Rancière, 2012, p. 25).

Nas universidades brasileiras, o estudo da cena expandida ainda é território novo. 
Há muita resistência e dificuldades financeiras para o desenvolvimento de laboratórios de pesquisa que deem conta da diversidade de projetos acadêmico-artísticos sobre o tema. Faltam equipamentos e infraestrutura, sobretudo nas universidades públicas, para a implementação de espaços adequados para laboratórios teórico -práticos, ficando a parte prática circunscrita a outros espaços físicos que fogem às condições adequadas para manutenção da pesquisa, muitas vezes fora dos muros da universidade, adaptados de forma a garantir a continuidade dos projetos. O mesmo ocorre, com menor limitação, com os trabalhos artísticos apresentados em teatros e em outros locais. Não temos a facilidade de experimentação técnica de um Wooster Group, de um Bob Wilson, de Castellucci, entre outros; faltam recursos financeiros que garantam a realização de ideias que são, em sua maioria, igualmente adaptadas, de forma criativa, às contingências dos percalços financeiros. Por outro lado, vemos surgir no Brasil, uma variedade grande de pesquisadores, artistas e companhias que investigam projetos ligados à intermedialidade. Não há hoje como negar a presença da cultura intermidiática na vida de crianças e jovens e isso tem um impacto direto na formação pedagógica, que parte não apenas do interesse natural do estudante sobre o tema, mas pelo modo de percepção do ambiente virtual no qual estamos inseridos, possibilitando novos modos de criação, manipulação e reinvenção de imagens em sua interação com os corpos na cena expandida. A sala de aula vê-se transformada por novos referenciais e dispositivos que antes limitavam-se a metodologias de criação a partir de técnicas e concepções mais facilmente localizáveis e determináveis, mas nem por isso menos instigantes e criativas. Mas o fato é que hoje as possibilidades de criação e recepção da cena intermedial extrapolam as práticas pedagógicas conhecidas e impõem a revisitação e a invenção de metodologias de ensino constantemente reelaboradas, a partir do contato in loco com uma gama muito grande de possibilidades diante de inúmeros dispositivos de imagens, de suportes diversos, da reunião de artistas provenientes de práticas bastante diferenciadas. Contrariamente a uma visão apocalíptica e não menos redutora de um isolamento crescente devido à irreversibilidade das tecnologias no cotidiano, o que nos leva, como Virilio aponta, talvez a uma ausência, ouso apostar em modos de aprendizagem que valorizem novas formas de criação, a partir de experimentações empíricas, sem abrir mão, contudo, de horizontes teóricos balizadores. 
Levanto algumas questões que me parecem ser desde já relevantes para as investigações sobre a cena expandida no ensino do teatro. Historicamente, Pluta aponta dois momentos importantes da cena intermedial: o primeiro nos anos de 1990, em que a tela de projeção ganha um status significativo nas análises sobre o tema; o segundo, a partir de 2005, em que a formação do ator passa a ser questionada diante da emergência de um pensamento crítico. A partir de então, há dois aspectos que convergem para o surgimento de uma nova formação do ator: a pluridisciplinaridade e interdisciplinaridade presentes nos currículos das principais escolas de teatro (as influências das artes visuais, da performance, da dança, da fotografia, da literatura, da filosofia, da sociologia, da física, etc.), que promovem uma desfronteirização dos limites artísticos e uma ampliação das relações entre as artes e as demais disciplinas; e a criação de laboratórios "em uma perspectiva interdiciplinar em confronto com o fenômeno da hibridização" (Pluta, 2015, p. 58). Pluta defende um laboratório transversal que permite a criação de metodologias visando à experimentação dos dispositivos, da performatividade; um espaço privilegiado que comporta a cena, a pesquisa e a tecnologia. Cita, como exemplo da fusão entre arte e ciência em laboratório, o trabalho desenvolvido pela dupla Julie Wilson-Bokowiec, performer e Mark Bokowiec, músico e designer eletrônico. Ambos criaram um dispositivo chamado Bodycoder, concebido por Mark, em 1995, que permite gravar e manipular a voz humana em um modo interativo, através do uso de uma luva e de um colete pela performer. O bodycoder precisa ser revisto e adaptado a cada nova performance, não se trata de um sistema fixo. Os artistas criaram o conceito kinésonique para descrever a criação do som pelo movimento corporal da performer em contato com o dispositivo. A metodologia de trabalho compreende a discussão da ideia da performance, a reconfiguração do Bodycoder, o processo de criação, uma apresentação da performance ainda em processo, os ensaios e a apresentação final. Corpo e tecnologia são completamente integrados no processo de criação que privilegia o espaço laboratorial como espaço necessário para o aprofundamento da experimentação e a observação de efeitos de presença - conceito primordial da cena expandida.

Outro exemplo de criação laboratorial é a instalação imersiva "Branco", criada em 
2012, pela dupla Mirella Brandi² e Muepetmo ${ }^{3}$, que explora diversas narrativas experimentais através das relações entre as artes cênicas, artes visuais, música e cinema expandido, com o objetivo de experimentar e provocar novas percepções espaço-temporais. A obra faz parte da trilogia das cores que teve início em 2006, quando os artistas receberam o convite do "Festival Live Cinema" para realizar a performance "Cinza". Em 2012, foram selecionados pelo "Rumos Itaú Cultural" e criaram "Branco". Atualmente, dedicam-se à criação de "Chumbo", ainda inédita.

Concebida para ser apresentada em espaços variados (exposições, teatros, salas, auditórios, etc), a performance "Branco" busca conduzir os espectadores em um caminho de "imersão visual", no qual cada espectador cria uma apreensão subjetiva da obra. Utilizando-se de névoa e fumaça e recebendo interferência direta de projeção de luzes diversas, "Branco" constrói uma dramaturgia visual sem utilizar telas ou outros suportes. A alteração da percepção espacial do espectador é conseguida pelos artistas através da manipulação de partículas de fumaça em contato com fontes de luz específicas. O áudio, realizado ao vivo, amplia, ainda mais, a qualidade perceptiva das imagens criadas, despertando uma ampla gama de sensações.

Muepetmo criou em laboratório o conceito de pesquisa chamado OAI (Orquestra de Áudio Instrumentos) que reúne composições gravadas em sampler de instrumentos acústicos para serem manipuladas ao vivo. O artista investiga, em espaços específicos, como a fisicalidade das ondas sonoras são capazes de provocar reações corporais no espectador. A hipótese é de que algumas características sonoras, ainda que inaudíveis, são capazes de alterar a percepção temporal.

Aprofundar nossos caminhos perceptivos através desta trilogia mudou todo o nosso olhar a respeito das possibilidades narrativas, inclusive quando se funde a outras linguagens artísticas, as mais diversas possíveis. A trilogia das cores nos proporcionou um caminho novo de linguagem e comunicação subjetiva que cresce e se fortifica a cada nova experiência, seja apenas entre a luz e a música, seja na fusão com outros artistas e linguagens. ${ }^{4}$

\footnotetext{
${ }^{2}$ Artista multimídia, designer de luz e diretora. Sócio-fundadora e diretora artística do Coletivo Phila 7.

3 Músico, produtor e compositor formado pelo Institute Áudio Engineering (SAE), na Holanda.

${ }^{4}$ Depoimento de Mirella Brandi, em 16 maio 2015, retirado da página da dupla no facebook. Disponível em: https://www.facebook.com/mirellabrandixmuepetmo. Acesso em: 10 set. 2015.
} 
Os laboratórios que tratam do teatro expandido reúnem pesquisas híbridas que exigem de seus participantes conhecimentos oriundos de outras disciplinas. O uso da tecnologia impõe, em muitos casos, apoio de técnicos em eletrônica, em engenharia digital, assim como o uso de softwares de edição, tratamento e projeção de imagens. Independente da metodologia adotada, a partir das especificidades de cada trabalho, é certo que se está diante de uma criação que reúne profissionais de áreas distintas. Outra questão é que tal empenho exige interação constante entre a equipe, em uma ação integrada na cena, o que significa a incorporação de todos em um processo de criação in loco. O dispositivo audiovisual, por exemplo, não pode ser apresentado posteriormente aos atores, ele é parte fundamental da elaboração das ações e das interrelações estabelecidas na cena. Assim também imagens produzidas a partir de um software, como o mapping, não deveriam ser realizadas separadamente à elaboração da própria cena. Arte, tecnologia e ciência, antes dissociadas, caminham juntas, deslocam-se em linhas transversais, borrando fronteiras e articulando modos híbridos de criação e recepção da cena.

\section{Referências Bibliográficas}

COUCHOT, Edmond. Automatização de técnicas figurativas: rumo à imagem autônoma. In: DOMINGUES, Diana (Org.). Arte, ciência e tecnologia. Passado, presente e desafios. São Paulo: Ed. da Unesp, 2009. p. 397-406.

DUBOIS, Philippe. Um "efeito cinema" na arte contemporânea. In: Dispositivos de registro na arte contemporânea. Rio de Janeiro: Contracapa Editora/ FAPERJ, 2009, pp. 179-216.

FÉRAL, Josette. Théorie et pratique du théâtre. Au-delà des limites. Montpellier, L'Éditions I'Entretemps, 2011.

FÉRAL, Josette (Org.). Pratiques Performatives. Body remix. Québec/Rennes: Presses de I'Université du Québec/Presses Universitaires de Rennes, 2012.

FERNANDES, Silvia. Teatralidades contemporâneas. São Paulo: Perspectiva, 2010

GARRAMUÑO, Florencia. Frutos Estranhos. Rio de Janeiro: Ed. Rocco, 2014

KAC, Eduardo. Telepresença e Bioarte. Humanos, coelhos \& Robôs em rede. São Paulo: EDUSP, 2013.

KRAUSS, Rosalind. Sculpture in the expanded field. In: Arte \& Ensaios, n. 17., Revista do programa de Pós-Graduação em Artes da UFRJ, 2008, p. 87-93. 
PARENTE, André. A forma cinema: variações e rupturas. In: Transcinemas. Rio de Janeiro: Contracapa Livraria, 2009.

PAVIS, Patrice. Dicionário de teatro. São Paulo: Perspectiva, 1999.

PLUTA, Izabella. L'acteur et l'intermédialité. Les nouveaux enjeux pour l'interprète et la scène à l'ère technologique. Lausanne: L'âge d'Homme, 2011.

PLUTA, Izabella. L'espace du laboratoire entre création technologique et recherche scientifique: prémices d'une méthodologie. In: Ligeia. Dossiê sur l'art. VIII ${ }^{\circ}$ Année, $n^{\circ}$ 137-140. Janvier-juin 2015, p. 47-58.

RANCIÈRE, Jacques. O espectador emancipado. São Paulo: Editora WMF Martins Fontes, 2012. 